\title{
respondence
}

\section{Hypertrophic cardiomyopathy: a common disease with a good prognosis}

Sir,

Shapiro and Zezulka in their recent paper (1983; 50: 530-3) draw conclusions regarding the prognosis of hypertrophic cardiomyopathy, which if substantiated would greatly alter the attitude to the disease of physician and patient alike. We would suggest, however, that the data presented provide a less substantive basis for the authors' conclusions than would at first appear.

No information is given regarding the presence or absence of hypertension in the patients studied. This omission is of great importance as hypertension is the commonest cause of secondary left ventricular hypertrophy. ${ }^{1}$ Furthermore, many of the patients would have been treated for their symptoms of angina and dyspnoea, and the drugs used (for example, beta blockers, nifedipine, nitrates, and diuretics) could have masked underlying hypertension even if the blood pressure appeared normal.

The authors acknowledge that only one third of their patients had the traditional features of hypertrophic cardiomyopathy - that is, asymmetrical septal hypertrophy and an outflow tract gradient. It would have been helpful if they had detailed the minimum combination(s) of angiographic findings that they considered necessary to establish the diagnosis of hypertrophic cardiomyopathy, thus permitting the reader independently to assess their differentiation of hypertrophic cardiomyopathy from other forms of ventricular hypertrophy. In this context it should be remembered that mitral regurgitation is itself a cause of left ventricular hypertrophy ${ }^{1}$ and that systolic cavity elimination may occur in ventricular hypertrophy due to other causes. ${ }^{2}$

The data regarding prognosis given by McKenna $e t a l$ in a series following 254 patients for a mean of six years ${ }^{3}$ can be compared with the data given by Shapiro and Zezulka, as McKenna et al give information on prognosis in different age groups. We may restrict attention to deaths classified as sudden or due to cardiac failure, in order to attain the greatest com- parability, and consider the mortality experience of Shapiro and Zezulka's 39 patients in the light of McKenna et al's 207 patients aged 15 or over; even when the sampling uncertainty of the death rate of 23.4 per 1000 patient years as shown by McKenna et al is disregarded, the absence of any deaths in 121 patient years would occur purely by sampling variation $5.9 \%$ of the time, and in the opposite tail of the distribution six or more deaths would occur $5.8 \%$ of the time; the discrepancy in outcome between the series should not be judged significant.

Thus we suggest that inadequate information is given $(a)$ to exclude the commonest cause of secondary ventricular hypertrophy and (b) objectively to assess the angiographic criteria which the authors used to reach a diagnosis of hypertrophic cardiomyopathy in the majority of their patients. Furthermore, when their data are examined quantitatively rather than intuitively they do not differ significantly from the prognosis previously reported.

\section{Andrew H Watt, \\ Department of Cardiology, \\ University Hospital of Wales, Cardiff.}

Robert G Newcombe, Department of Medical Computing Statistics, Welsh National School of Medicine, Cardiff.

\section{References}

1 Rowlands DJ. Understanding the electrocardiogram: section 2: Morphological abnormalities. Macclesfield: Imperial Chemical Industries, 1982: 150.

2 Raizner AE, Chahine RA, Ishimori T, Awdeh M. Clinical correlates of left ventricular cavity obliteration. Am $\mathcal{F}$ Cardiol 1977; 40: 303-9.

3 McKenna W, Deanfield J, Faruqui A, England D, Oakley C, Goodwin J. Prognosis in hypertrophic cardiomyopathy: role of age and clinical, electrocardiographic and hemodynamic features. Am $\mathcal{F}$ Cardiol 1981; 47: 532-8. 
This letter was shown to the authors, who reply as follows:

In our study the diagnosis of hypertrophic cardiomyopathy was not based on the classical features of asymmetrical septal hypertrophy and left ventricular outflow tract obstruction but was made in the presence of left ventricular hypertrophy of unknown aetiology. Exclusion of hypertension is the greatest problem when studying hypertrophic cardiomyopathy, and a deliberate attempt was made to do this and to exclude other secondary causes of left ventricular hypertrophy.
We would not wish to draw definitive con lusions from our work but could not help by being impressed that none of our patients died during a thi ee $y \mathrm{ca}$; period. We believe that this does warrant fu the: investigation and study since we agree with $D \cdot r / a t t$ and Newcombe that if other authors find simi!ar results to our own this would greatly alter the avi'nde to the disease of both physicians and patients.
Dr L M Shapiro,
National Heart Hospital,
Westmoreland Street,
London WIM 8BA.
Dr A Zezulka,
Dudley Road Hospital, Birmingham 18

\section{Morphological appearance of atherosclerotic lesions of the coronary arteries}

Sir,

Pidgeon et al (1984; 51: 125-9) correctly point out that "coronary atheroma is present more often and is more widely distributed in the coronary tree than is indicated by coronary angiography." Perhaps your readers would be interested in the following historical facts.

My teacher, H Gideon Wells, professor of pathology, University of Chicago, taught that the collapsed coronary artery seen at necropsy was frequently inconsistent with either the clinical history or the state of the myocardium. For this reason "In order to determine the configuration of the lesions of the coronary arteries under living conditions, they were examined roentgenologically when distended with an injection mass of a suspension of barium sulfate, Tragacanth and water at mean aortic pressure." $\mathrm{He}$ subsequently published ${ }^{1}$ illustrations showing the differences between the postmortem collapse of the coronary vessel at the site of an atherosclerotic lesion and the appearance of the same region of the coronary vessel when it distended with contrast substance. He concluded that one must take into consideration these changes when evaluating findings at necropsy.
It was Thoma's ${ }^{2}$ concept that medial atrophy produced dilatation of the vessel at the site of atherosclerosis which lead Wells to perform his experiments proving the correctness of Thoma's brilliant concept of the morphological appearance of the atherosclerotic lesion in the living.

Louis A Soloff,

Division of Cardiology,

Temple University Health Sciences Center, Philadelphia,

Pennsylvania 19140, USA

\section{References}

1 Stewart JD, Birchwood E, Wells HG. The effect of atherosclerotic plaques on the diameter of the lumen of coronary arteries. FAMA 1935; 104: 731-3.

2 Thoma R. Ueber die Abhängigkeit der Bindegewebsneubildung in der Arterienintima von den mechanischen Bedingungen des Blutumlaufes. Archiv für pathologische Anatomie und Physiologie, und für klinische medicin 1886; 104: 209-41.

\section{Notices}

\section{Pediatric Cardiology}

The Second World Congress of Pediatric Cardiology will be held from 2 to 6 June 1985 at the Waldorf Astoria Hotel, New York. Further information may be obtained from: Virginia Herlitz, 404 Park Avenue South, New York, NY 10016, USA.

\section{British Cardiac Society}

The Autumn Meeting will be held at the Wembley Conference Centre, London, on 3 and 4 December 1984 , and the closing date for receipt of abstracts will be 15 August 1984.

The Annual General Meeting for 1985 will take place in Birmingham on 17 and 18 April 1985, and the closing date for receipt of abstracts will be 8 January 1985. 